\title{
Safety of belimumab in association with denosumab in a patient affected by Lupus Erythematosus: a case report
}

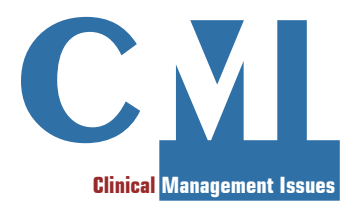

Marco Scarati ${ }^{1}$, Simone Parisi ${ }^{1}$, Richard Borrelli ${ }^{1}$, Maria Bruzzone ${ }^{1}$, Marta Priora ${ }^{1}$, Clara Lisa Peroni ${ }^{1}$, Enrico Fusaro ${ }^{1}$

\begin{abstract}
Systemic Lupus Erythematosus (SLE) is a chronic autoimmune disease characterized by multisystemic involvement. Owing to multifactorial etiologies, low bone mineral density (BMD) osteoporosis $(\mathrm{OP})$ and fragility fractures $(\mathrm{FFx})$ have been very frequently documented in these patients. Appropriate treatments to minimize underlying immunologic disease activity remain mandatory, and the development of strategies to prevent and treat important complications as osteoporosis is needed.

We present the clinical case of a female SLE patient treated simultaneously with belimumab (anti-BLyS) for the underlying disease, and denosumab (anti-RANKL) for concomitant severe osteoporosis. As these monoclonal antibodies have been recently introduced into the market, their combination has not been reported in literature yet. In this case, the combined administration proved a viable option for a SLE patient with osteoporosis and bisphosphonates contraindications.
\end{abstract}

Keywords: Lupus Erythematosus, Systemic; Belimumab; Denosumab

Sicurezza di belimumab in associazione a denosumab in una paziente affetta da lupus eritematoso: un caso clinico

CMI 2017; 11(1): 39-43

https://doi.org/10.7175/cmi.v11i1.1286

\section{INTRODUCTION}

Systemic lupus erythematosus (SLE) is a heterogeneous autoimmune disorder characterized by multisystemic involvement. Although the exact etiology has not been determined, it has been shown that genetic, environmental, and hormonal factors play a role in its pathogenesis. SLE is characterized by disturbances of both innate and adaptive immune systems, with dysregulation of $\mathrm{T}$ and $\mathrm{B}$ cells, cytokines secretion, and autoantibodies production [1]. Its prevalence ranges from 40 to 200 cases per 100,000 [2]. Women are affected by SLE nine times more frequently than men, particularly after puberty and before menopause [2]. For reasons not entirely understood, SLE is also more frequent in certain ethnic groups, e.g. African-Americans and Hispanics [2]. The broad spectrum of clinical presentations makes the SLE the prototypic multisystem

Why we describe this case

The occurrence of osteoporosis in SLE patients has been widely described in literature. However, often in SLE patients kidney dysfunction or kidney failure concur, for which bisphosphonates are contraindicated. Therefore, it is mandatory to find osteoporosis treatments compatible with the therapy for the underlying disease
Rheumatology Unit. Azienda OspedalieroUniversitaria Città della Salute e della Scienza di Torino
Corresponding author Marco Scarati mscarati@cittadellasalute.to.it

\section{Disclosure}

This article has been published with the unconditional support of GlaxoSmithKline S.p.A. SP reports personal fees from Pfizer, Abbvie, MSD, outside the submitted work. $\mathrm{EF}$ reports personal fees from Actelion, Abbvie, MSD,

Sobi, Pfizer, and Italfarmaco, outside the submitted work. 


\begin{tabular}{|l|c|c|}
\hline \multicolumn{1}{|c|}{ Parameter } & \multicolumn{1}{c|}{ Detected value } & Normal values \\
\hline WBC (n/l) & 2800 & $4000-10,000$ \\
Neutrophils (n/l) & 1800 & $1500-8000$ \\
Lymphocytes (n/l) & 800 & $1000-4000$ \\
PLTs (n/l) & 98,000 & $140,000-450,000$ \\
ANA & $1 / 160$ & $<1 / 80$ \\
Anti-dsDNA (UI/) & 89 & $<10$ \\
C3 (mg/dl) & 25 & 83 \\
C4 (mg/dl) & 8 & 15 \\
\hline
\end{tabular}

Table I. Laboratory analyses performed in 2004

$\mathrm{ANA}=$ antinuclear antibodies;

Anti-dsDNA = antidouble-stranded DNA; PLTs = platelets: $\mathrm{WBC}=$ White Blood Cells
The etiology of bone loss in SLE is supposed to be multifactorial, including traditional osteoporosis risk factors, inflammation, contraindications to sun exposure and subsequent reduction of activation of vitamin D, metabolic factors, hormonal factors, serologic factors, and medication-induced adverse effects $[12,14,15]$.

We report the case of a woman affected by SLE and severe osteoporosis with osteoporotic fractures, contraindication to bisphosphonates due to a history of renal insufficiency, and concomitantly treated with belimumab and denosumab, two recently marketed monoclonal antibodies. Belimumab's mechanism of action is based on the known pathological functions of $B$ lymphocyte stimulator (BLyS), a tumor necrosis factor (TNF) superfamily ligand. BLyS plays a critical role in the development and homeostasis of B lymphocytes. Under pathological conditions (as occurs in SLE), $\mathrm{B}$ lymphocytes produce the auto-antibodies responsible for the clinical features of SLE. By inhibiting BLyS, belimumab is able to effectively block this pathological pathway $[8,16,17]$. Denosumab is an anti-receptor activator of nuclear factor-kappaB (NFKB) ligand antibody, a fully human monoclonal antibody that binds the cytokine RANKL (receptor activator of NFKB ligand), an essential factor initiating bone turnover. RANKL inhibition blocks osteoclast maturation, function and survival, thus reducing bone resorption [18-20].

To date, there are no studies in literature on the efficacy and safety of combination therapy with belimumab and denosumab. This is probably due to the recent introduction on the market of these monoclonal antibodies.

\section{CASE PRESENTATION}

We report the case of a 54-year-old female patient. In 2004, she came to our attention with malar rash, migratory arthralgias, recurrent epistaxis, and morning articular stiffness lasting more than one hour. Her previous medical history was significant for arterial hypertension, turbinate hypertrophy, and occasional leukopenia.

Laboratory analyses showed leukopenia, thrombocytopenia with antinuclear antibodies (ANA) $=1 / 160$ with granular pattern on immunofluorescence, anti-dsDNA positive, hypocomplementemia (Table I), presence of 


\begin{tabular}{|c|c|c|c|c|c|}
\hline & $\begin{array}{c}\text { March } \\
\text { 2014 - first } \\
\text { administration of } \\
\text { belimumah }\end{array}$ & $\begin{array}{l}\text { August } 2014- \\
\text { after } 5 \text { months } \\
\text { of therapy with } \\
\text { helimumah }\end{array}$ & $\begin{array}{l}\text { December } \\
2014 \text { - first } \\
\text { administration of } \\
\text { denosumab }\end{array}$ & $\begin{array}{l}\text { June } 2015 \text { - after six } \\
\text { months of belimumab/ } \\
\text { denosumab combined } \\
\text { therapy }\end{array}$ & $\begin{array}{c}\text { December } 2016 \\
\text { - last visit }\end{array}$ \\
\hline SLEDAI & 13 & 10 & - & 6 & 6 \\
\hline WBC (n/l) & 3340 & 3216 & 3412 & 3945 & 6440 \\
\hline$H B(g / d l)$ & 10.9 & 11.1 & 11 & 11.4 & 10.4 \\
\hline PLTs (n/l) & 130,000 & 126,000 & 146,000 & 126,000 & 254,000 \\
\hline Creatinine $(\mathrm{mg} / \mathrm{dl})$ & 1.89 & 1.95 & 2.01 & 2.05 & 1.71 \\
\hline Proteinuria & no & no & no & no & no \\
\hline C3 (mg/dl) & 32 & 79 & 82 & 68 & 85 \\
\hline $\mathrm{C} 4$ (mg/dl) & 11 & 18 & 21 & 17 & 12 \\
\hline Arthritis & yes & no & no & no & no \\
\hline ANA & $1 / 640$ & $1 / 320$ & 1/3२० & $1 / 640$ & $1 / 320$ \\
\hline Anti-dsDNA (UI/I) & 72 & 22 & 40 & 64 & 38 \\
\hline
\end{tabular}

lupus anticoagulant antibodies and antibeta2-glycoprotein I IgG, and anticardiolipin IgG positive at low levels.

After a deep vein thrombosis with pulmonary thromboembolism, the patient had to start warfarin therapy. Furthermore, a MRI of the encephalon, requested for the suspicion of neurological involvement, showed signs of microischemic strokes.

According to the ACR 1997 criteria, a diagnosis of SLE was made, and the patient started a therapy with prednisone (initially at high dose, $25 \mathrm{mg} / \mathrm{die}$ ) and hydroxychloroquine $(200 \mathrm{mg} / \mathrm{die})$, while awaiting the therapy with cyclophosphamide, which was started in September 2004 and shortly afterwards suspended owing to pancytopenia and gastrointestinal intolerance.

Due to incomplete disease control with steroid and hydroxychloroquine therapy (hypocomplementemia, anemia, and arthralgia were still present) she was given a therapy based on azathioprine, which was suspended, alongside hydroxychloroquine, because of the worsening of leukopenia ( $\mathrm{Au}-$ gust 2005). From 2005 to 2013, the disease went to partial remission with steroid only therapy (treatment range between 10 and $12.5 \mathrm{mg} / \mathrm{die}$ ).

In March 2013, during treatment with prednisone $12.5 \mathrm{mg} / \mathrm{die}$, her renal function worsened: serum creatinine was $3.1 \mathrm{mg} / \mathrm{dl}$ and proteinuria increased to $0.9 \mathrm{~g} / 24$ hours. Even though lupus nephritis was suspected, renal biopsy was not performed because serum creatinine and proteinuria decreased after starting ACE-inhibitors; however, bisphosphonates, that she had been taking since 2011 for a high risk of bone fracture documented by a dual-energy X-ray absorptiometry (DXA) with a vertebral T-score -3.0, were suspended. As osteoporosis-prophylaxis, the patient continued therapy with calcium carbonate and vitamin $\mathrm{D}$ (calcifediol).

Alongside ACE-inhibitor treatment, she started therapy with mycophenolate $(500 \mathrm{mg}$ twice a day) and her serum creatinine stabilized, reaching mean values $=1.2-1.4 \mathrm{mg} / \mathrm{dl}$, denoting stage 2 renal insufficiency according to Kidney Disease Outcomes Quality Initiative (NKF KDOQI) ${ }^{\mathrm{TM}}$ classification.

In February 2014, mycophenolate was suspended for gastrointestinal intolerance and a mild non erosive poliarthritis; her renal situation was stable, with no proteinuria.

She presented in March 2014 with antidsDNA persistently positive (Table II), low complement levels, persistent fatigue, and oligoarthritis on wrists and small joints of the hand.

After proper literature searches and discussion with nephrologists, she was given a therapy with belimumab (Benlysta ${ }^{\circledR}$ ) at the dosage of $10 \mathrm{mg} / \mathrm{kg}$ (600 mg) once every month.

After six infusions, in August 2014 the patient had a good clinical and serological response: no drug adverse event arose during treatment, arthritis reached clinical remission, renal function (creatininemia and proteinuria) remained satisfactory, and no flares of SLE had happened. Complement levels improved (Table II), anti-dsDNA reduced, no hematological alterations occurred, and total dosage of prednisone could be reduced to $7.5 \mathrm{mg} /$ die.
Table II. Laboratory analyses performed from March 2014 to December 2016

ANA = antinuclear antibodies;

Anti-dsDNA = anti-doublestranded DNA;

$\mathrm{HB}=$ hemoglobin;

PLTs = platelets;

SLEDAI = Systemic Lupus Erythematosus Disease

Activity Index;

$\mathrm{WBC}=$ White Blood Cells 
In December 2014, the patient had a spontaneous rib fracture and right metatarsal heads stress fractures. Dual-energy X-ray absorptiometry (DXA) showed reduced bone mineral density with vertebral $\mathrm{T}$-Score $=-3.2$. At that time, her osteoporosis was treated with calcifediol 50.000/UI per month and calcium carbonate every day. Bisphosphonates were suspended due to contraindications for renal insufficiency. Given this clinical picture, the patient started denosumab (Prolia ${ }^{\circledR}$ ) $60 \mathrm{mg}$ administered as a single subcutaneous injection once every 6 months, in association with calcium $1000 \mathrm{mg}$ daily and supplementation of already set vitamin D.

In February 2016, DXA documented a vertebral T-score $=-1.7$. No new spontaneous fractures occurred. The patient continued the treatment with belimumab $10 \mathrm{mg} / \mathrm{kg} /$ month and denosumab $60 \mathrm{mg} / 6 \mathrm{month}$, and we could reduce the dosage of prednisone to $5 \mathrm{mg} /$ die. To date, she has had thirty-two infusions of belimumab and five injections of denosumab.

\section{DISCUSSION AND CONCLUSION}

In literature, there are no case reports about the concurrent use of two monoclonal antibodies as belimumab and denosumab.

The etiology of bone loss in SLE is supposed to be multifactorial, including traditional osteoporosis risk factors, inflamma- tion, metabolic factors, and medication-induced adverse effects. Osteoporotic fractures are present in 20-26.1\% of SLE patients and often an appropriate treatment is mandatory. At the same time, a large number of SLE patients suffer from many comorbidities and many organ involvement by the underlying disease $[2,3,11,12,14]$ : therefore, they need a basic therapy able to ensure an absent or a low SLE disease activity, and at the same time an appropriate therapy for the osteopenia/osteoporosis. Nowadays, an increasing number of patients are treated with belimumab, due to its proven efficacy in reducing flares. As a result, case reports and trials concerning this association and its interactions are required.

In this case report, the treatment with belimumab and denosumab resulted in improved patient's conditions. By considering the mechanisms of action of the two drugs (anti-RANKL and anti-BLyS), we do believe that the combined administration could be a viable option for patients with SLE, osteoporosis, and bisphosphonates contraindications. Finally, the six-month administration of denosumab is particularly suitable for patients who are exhausted because of their multiple chronic therapies; furthermore, it ensures an effective alternative therapy, since no side effects concerning kidneys (as opposed to bisphosphonates) and hearth (a known side effect of strontium ranelate) were detected.

Key points

- Etiology of bone loss in systemic lupus erythematosus (SLE) is multifactorial, including traditional osteoporosis risk factors, inflammation, metabolic factors, and medication induced adverse effects

- In SLE patients, often kidney dysfunction or kidney failure concur, thereby contraindicating the use of bisphosphonates

- Considering the mechanisms of action of belimumab (anti-BLyS) and denosumab (anti$R A N K L)$, two monoclonal antibodies acting upon two different molecular pathways, combined administration could be a worth option to be considered for patients with SLE, renal insufficiency, and osteoporosis

\section{REFERENCES}

1. Rahman A, Isenberg DA. Systemic lupus erythematosus. N Engl J Med 2008; 358: 929-39; https://doi.org/10.1056/NEJMra071297

2. Vilas-Boas A, Morais SA, Isenberg DA. Belimumab in systemic lupus erythematosus. RMD Open 2015; 1: e000011; https://doi.org/10.1136/rmdopen-2014-000011 
3. Larosa M, Iaccarino L, Gatto M, et al. Advances in the diagnosis and classification of systemic lupus erythematosus. Expert Rev Clin Immunol 2016; 12: 1309-20 https://doi.org/10.1080/17 44666x.2016.1206470

4. Kuhn A, Bonsmann G, Anders HJ, et al. The diagnosis and treatment of systemic lupus erythematosus. Dtsch Arztebl Int 2015;112: 423-32; https://doi.org/10.3238/arztebl.2015.0423

5. Petri M, Orbai AM, Alarcón GS, et al. Derivation and validation of Systemic Lupus International Collaborating Clinics Classification Criteria for Systemic Lupus Erythematosus. Arthritis Rheum 2012; 64: 2677-86; https://doi.org/10.1002/art.34473

6. Hochberg MC. Updating the American College of Rheumatology revised criteria for the classification of systemic lupus erythematosus. Arthritis Rheum 1997; 40: 1725; https://doi. org/10.1002/art.1780400928

7. Yu C, Gershwin ME, Chang C. Diagnostic criteria for systemic lupus erythematosus: a critical review. J Autoimmun 2014; 48-9: 10-3; https://doi.org/10.1016/j.jaut.2014.01.004

8. Yee CS, Crabtree N, Skan J, et al. Prevalence and predictors of fragility fractures in systemic lupus erythematosus. Ann Rheum Dis 2005; 64: 111-3; https://doi.org/10.1136/ard.2003.018127

9. Bultink IE, Lems WF. Systemic lupus erythematosus and fractures. RMD Open 2015; 1(Suppl 1): e000069; https://doi.org/10.1136/rmdopen-2015-000069

10. Rentero ML, Amigo E, Chozas N, et al; GHDP study group. Prevalence of fractures in women with rheumatoid arthritis and/or systemic lupus erythematosus on chronic glucocorticoid therapy. BMC Musculoskelet Disord 2015; 16: 300; https://doi.org/10.1186/s12891-015-0733-9

11. Cramarossa G, Urowitz MB, Su J, et al. Prevalence and associated factors of low bone mass in adults with systemic lupus erythematosus. Lupus 2016 Aug 13 [Epub ahead of print]; https:// doi.org/10.1177/0961203316664597

12. Carli L, Tani C, Spera V, et al. Risk factors for osteoporosis and fragility fractures in patients with systemic lupus erythematosus. Lupus Sci Med 2016; 3: e000098; https://doi.org/10.1136/ lupus-2015-000098

13. Salman-Monte TC, Torrente-Segarra V, Muñoz-Ortego J, et al. Prevalence and predictors of low bone density and fragility fractures in women with systemic lupus erythematosus in a Mediterranean region. J Rheumatol Int 2015; 35: 509-15; https://doi.org/10.1007/s00296014-3087-y

14. Bultink IEM. Osteoporosis and fractures in systemic lupus erythematosus. Arthritis Care Res 2012; 64: 2-8; https://doi.org/10.1002/acr.20568

15. Di Munno O, Mazzantini M, Delle Sedie A, et al. Risk factors for osteoporosis in female patients with systemic lupus erythematosus. Lupus 2004; 3: 724-30; https://doi. org/10.1191/09612033031u1097oa

16. Vincent FB, Morand EF, Schneider P, et al. The BAFF/APRIL system in SLE pathogenesis. Nat Rev Rheumatol 2014; 10: 365-73; https://doi.org/10.1038/nrrheum.2014.33

17. Collins CE, Dall'Era M, Kan H, et al. Response to belimumab among patients with systemic lupus erythematosus in clinical practice settings: 24-month results from the OBSErve study in the USA. Lupus Sci Med 2016; 3: e000118; https://doi.org/10.1136/lupus-2015-000118

18. Hanley DA, Adachi JD, Bell A, et al. Denosumab: mechanism of action and clinical outcomes. Int J Clin Pract. 2012; 66: 1139-46; https://doi.org/10.1111/ijcp.12022

19. Suresh E, Abrahamsen B. Denosumab: a novel antiresorptive drug for osteoporosis. Cleve Clin JMed 2015; 82: 105-14; https://doi.org/10.3949/ccjm.82a.13173

20. Törring O. Effects of denosumab on bone density, mass and strength in women with postmenopausal osteoporosis. Ther Adv Musculoskelet Dis 2015; 7: 88-102; https://doi. org/10.1177/1759720X15579189 